\title{
Mapeamento das dissertações sobre Modelagem Matemática produzidas no Mestrado Profissional em Matemática em Rede Nacional
}

\author{
Mapping of dissertations on Mathematical Modelling Produced in the \\ Professional Master in Mathematics on National Network
}

\author{
Moisés Ceni de Almeida \\ Leonardo Maricato Musmanno \\ Sérgio Gonçalves de Sousa
} \begin{abstract}
Matemática e sua aplicação, teórica e prática, em todos os níveis de ensino, incluindo na formação continuada de professores de Matemática. Percebe-se que há aumento das produções nos últimos anos, em sua maioria, apresentando temas direcionados ao Ensino Médio, sem discutir, contudo, a importância da Modelagem Matemática como ferramenta de ensino.
\end{abstract}

Resumo: 0 artigo apresenta um mapeamento quanti-qualitativo das dissertações elaboradas no Mestrado Profissional em Matemática em Rede Nacional (PROFMAT) produzidas nos últimos sete anos, cujo objeto de estudo tenha abordado Modelagem Matemática. 0 objetivo desse mapeamento foi obter, no âmbito quantitativo, uma visão geral das pesquisas nas dissertações e, qualitativamente, se abordam o tema dentro de uma perspectiva de metodologia de ensino. 0 mapeamento identificou os conteúdos mais abordados e a distribuição das produções por nível de escolaridade, ano de publicação, regiões, estados e instituições, permitindo verificar a evolução dos trabalhos e possíveis lacunas. Foram investigadas 140 dissertações sobre Modelagem

Palavras-chave: Modelagem Matemática. Educação Matemática. PROFMAT.

Abstract: This article presents a quanti-qualitative mapping of the dissertations elaborated in the Professional Master's Program in Mathematics in National Network (PROFMAT) produced in the last seven years, whose object of study was Mathematical Modeling. The objective was to obtain, in the quantitative scope, an overview of research in the dissertations and, qualitatively, to verify if the subject is approached from a teaching methodology perspective. The mapping identified the most discussed contents and the distribution of productions by education level, year of publication, regions, states and institutions, allowing us to verify the evolution of the works and possible deficiencies. In total, 140 dissertations on Mathematical Modeling were investigated at all education levels, including the continuing education of mathematics teachers. It was noticed there has been an increase in production in recent years, mostly presenting themes aimed at high school, without discussing, however, the importance of Mathematical Modeling as a teaching tool.
Moisés Ceni de Almeida Doutor em Engenharia Mecânica. Professor do Instituto Federal de Educação Ciência e Tecnologia do Rio de Janeiro (IFRJ), campus Paracambi. Rio de Janeiro, Brasil. (iD) orcid.org/0000-0002-6170-2036 $\triangle$ moisesceni@gmail.com Leonardo Maricato Musmanno Doutor em Ciências da Computação. Professor do Instituto de Aplicação Fernando Rodrigues da Silveira (CAp) da Universidade do Estado do Rio de Janeiro (UERJ). Rio de Janeiro, Brasil.

(iD) orcid.org/0000-0002-1657-7408

$\triangle$ leonardo.musmanno@gmail.com

Sérgio Gonçalves de Sousa Mestre em Matemática. Professor do Instituto de Aplicação Fernando Rodrigues da Silveira (CAp) da Universidade do Estado do Rio de Janeiro (UERJ). Rio de Janeiro, Brasil. (iD) orcid.org/0000-0001-8717-8853 $\triangle$ sergio.sousa@uerj.br

Recebido em 08/06/2020 Aceito em 02/98/2020 Publicado em 09/09/2020

Keywords: Mathematical Modelling. Mathematical Education. PROFMAT. 


\section{Introdução}

Nos dias atuais, é cada vez mais comum esperar que o professor de Matemática aborde os conteúdos de sua disciplina de uma forma mais conectada ao cotidiano do aluno, buscando tornar suas aulas mais atrativas e interessantes para seu público.

Na prática pedagógica matemática, especialmente nos ensinos Fundamental e Médio, a questão da atratividade e da aplicabilidade dos conteúdos está relacionada ao porquê de se estudar Matemática. No estudo de funções, trigonometria, geometria e afins, o objetivo é apenas desenvolver as habilidades intelectuais do aluno, sem preocupar-se com as suas aplicações? Ou o foco do ensino deveria ser a capacitação do aluno para aplicar seus conhecimentos no seu diaa-dia? Bassanezi (2010) entende que

os professores devem valorizar o que ensinam de modo que o conhecimento seja ao mesmo tempo interessante, por ser útil, e estimulante, por ser fonte de prazer. Assim, o que propomos é a busca da construção de uma prática de ensino-aprendizagem matemática que combine "jogos" e resultados práticos. A matemática não deve ser considerada importante simplesmente por alguma definição arbitrária ou porque mais tarde ela poderá ser aplicada. Sua importância deve residir no fato de poder ser tão agradável quanto interessante. (BASSANEZI, 2010, p. 16)

A Modelagem Matemática surge neste contexto como uma ferramenta que pode auxiliar os professores nas duas frentes mencionadas: tornar suas aulas mais interessantes, visto que lida com temas que têm maior relação com a vida do aluno, e mostrar explicitamente como a Matemática pode ser aplicada no seu dia a dia.

O processo de modelagem, segundo a concepção de Bassanezi (2010), começa com a escolha de um tema ou de uma situação-problema, seguida de uma coleta de dados que podem ser qualitativos ou quantitativos, dependendo do tipo de situação-problema em estudo. Os dados coletados devem então ser organizados em tabelas/quadros para que a análise seja mais eficiente. A partir disso, é possível obter uma melhor informação para a elaboração de um modelo matemático mais adequado para resolver o problema ou a situação-problema escolhida. Em seguida, inicia-se a fase mais laboriosa do processo de Modelagem: a representação da situaçãoproblema em linguagem matemática. Ao final dessa etapa, espera-se obter um conjunto de representações matemáticas que possibilitem uma resolução adequada para o problema em questão, ou seja, a formulação de um modelo matemático.

Terminada a formulação do modelo matemático, inicia-se a resolução do problema em estudo. A resolução passa, então, por uma validação e avaliação do modelo construído, com 0 
objetivo de verificar se é viável utilizá-lo. Nesse momento, inicia-se uma análise crítica das soluções encontradas, abrindo espaço para discussões.

Como pode ser visto pelo exposto acima, a Modelagem transforma 0 aluno em ator principal no processo de construção de sua aprendizagem, levando-o a buscar ativamente as respostas da situação-problema apresentada. Nesse contexto, o professor deixa o seu papel tradicional de detentor do saber e passa atuar como orientador do processo de ensino, ajudando os alunos a selecionar e organizar informações, elaborando hipóteses e problemas, sugerindo meios de resolução, e mobilizando conhecimentos já adquiridos (COSTA, 2016). Além de tornar o aluno um protagonista ativo na construção do conhecimento, a utilização da Modelagem Matemática em sala de aula aproxima a Matemática escolar daquela que o estudante encontra em seu dia a dia, uma vez que explora problemas do mundo real.

O uso da Modelagem Matemática em sala de aula pode ainda auxiliar o professor a atender às expectativas presentes na Base Nacional Comum Curricular (BNCC) quando se refere às competências gerais da educação básica, dentre as quais destacamos:

\footnotetext{
Valorizar os conhecimentos historicamente construídos. Exercitar a curiosidade. Compreender, utilizar e criar tecnologias digitais da informação. Valorizar a diversidade de saberes. Argumentar com base em fatos, dados e informações confiáveis, para formular, negociar e defender ideias, pontos de vista e decisões comuns que respeitem e promovam os direitos humanos, a consciência socioambiental e o consumo responsável em âmbito local, regional e global, com posicionamento ético em relação ao cuidado de si mesmo, dos outros e do planeta. Agir pessoal e coletivamente com autonomia, responsabilidade, flexibilidade, resiliência e determinação, tomando decisões com base em princípios éticos, democráticos, inclusivos, sustentáveis e solidários. (BRASIL, 2018, p. 9-10)
}

O trabalho com Modelagem pode melhorar a capacidade de interpretação do aluno, além de fazer com que ele assuma uma posição crítica ao tentar resolver as diversas situaçõesproblema as quais será exposto. Este tipo de trabalho também o leva a analisar o número de soluções possíveis para o problema e compreender que há vários caminhos possíveis para chegar à solução. Cabe ressaltar que esta postura ativa diante de problemas é importante para a solução de situações vividas por todos em nosso cotidiano. A Modelagem Matemática, portanto, tem 0 potencial de promover a autonomia do cidadão, de forma que, ao se deparar com problemas econômicos, no comércio, na medicina ou em qualquer outra situação diária, possa resolvê-los de forma eficiente e precisa.

Ao utilizar a Modelagem Matemática em sala de aula podemos proporcionar ao aluno a 
possibilidade de desenvolver seus conhecimentos de forma contextualizada e integrada a outros conhecimentos, além de contribuir no desenvolvimento de competências e habilidades fundamentais (BRASIL, 2018). Por esses motivos, acreditamos que a Modelagem Matemática pode ser vista como uma valiosa ferramenta metodológica para os processos de ensino e de aprendizagem de conteúdos matemáticos. Sobre o ambiente de Modelagem, Sonego (2009) entende que "o aluno é incentivado a trabalhar em grupo, possibilitando o convívio social e o desenvolvimento do senso de cooperação, responsabilidade, criticidade e comunicação oral entre os membros do grupo" (p. 21).

Assim, considerando a importância do tema para os processos de ensinar e de aprender, neste trabalho nos propusemos a realizar um mapeamento das dissertações que exploram o tema da Modelagem Matemática. Para isso, realizamos uma busca no repositório virtual do curso de Mestrado Profissional em Matemática em Rede Nacional (PROFMAT), tendo sido encontrados 140 trabalhos, os quais foram analisados com o objetivo de obter, no âmbito quantitativo, uma visão geral das pesquisas nas dissertações e, no âmbito qualitativo, se abordam o tema dentro de uma perspectiva de metodologia de ensino. O mapeamento identificou os conteúdos mais abordados e a distribuição das produções por nível de escolaridade, ano de publicação, regiões, estados e instituições, permitindo verificar a evolução dos trabalhos e possíveis lacunas. A Modelagem Matemática vem sendo usada com sucesso na resolução de problemas de diferentes áreas. Neste trabalho, entretanto, nosso enfoque será na Modelagem Matemática enquanto metodologia de ensino.

O texto está organizado nas seguintes seções: Modelagem Matemática no Brasil, na qual é apresentada o desenvolvimento dessa metodologia de ensino no país; PROFMAT, seção em que esse programa de pós-graduação é apresentado ao leitor, assim como algumas críticas a respeito; Aspectos Metodológicos, onde explicitamos brevemente o entendimento de mapeamento sobre o qual nos fundamentamos; Visão Global dos Dados, em que apresentamos os resultados obtidos e são realizadas análises sobre as informações colhidas a partir do mapeamento. $\mathrm{Na}$ seção de Conclusão é apresentado um resumo dos principais resultados obtidos no mapeamento e nossas considerações finais.

\section{Modelagem Matemática no Brasil}

O termo Modelagem Matemática como processo para descrever, formular, modelar e 
resolver uma situação problema de alguma área do conhecimento encontra-se já no início do século XX na literatura de Engenharia e Ciências Econômicas (BIEMBENGUT, 2009). Segundo Costa (2016), Modelagem Matemática pode ser compreendida como uma estratégia de ensino que possibilita ao aluno abordar conteúdos matemáticos a partir de fenômenos de sua realidade.

No Brasil, em meados da década de 1970 e início da década de 1980, a Modelagem Matemática contou com a importante colaboração de professores para firmar e difundir suas ideias na Educação Matemática brasileira. Professores e pesquisadores como Aristides Camargo Barreto, Rodney Carlos Bassanezi, Ubiratan D’Ambrósio e outros, que iniciaram o movimento da Modelagem Matemática, conquistaram seguidores por todo o país, promovendo uma reflexão sobre como se faz e como se ensina Matemática usando um modelo matemático, fazendo surgir a linha de pesquisa sobre Modelagem Matemática no ensino brasileiro.

A Modelagem na Educação Matemática é, como visto acima, uma prática recente no Brasil. No início do novo século, com a consolidação das recomendações propostas pelos Parâmetros Curriculares Nacionais (PCN), a Modelagem Matemática passa a ser efetivamente utilizada por professores em sua prática de ensino, tendo em vista sua relação com as orientações desses documentos e também com o reconhecimento do aluno como protagonista na construção do seu conhecimento. Nos últimos anos, com o advento da BNCC, a Modelagem é reforçada como um processo enriquecedor, como podemos observar no seguinte excerto:

\footnotetext{
Os processos matemáticos de resolução de problemas, de investigação, de desenvolvimento de projetos e da modelagem podem ser citados como formas privilegiadas da atividade matemática, motivo pelo qual são, ao mesmo tempo, objeto e estratégia para a aprendizagem ao longo de todo o Ensino Fundamental. Esses processos de aprendizagem são potencialmente ricos para o desenvolvimento de competências fundamentais para o letramento matemático (raciocínio, representação, comunicação e argumentação) e para 0 desenvolvimento do pensamento computacional. (BRASIL, 2018, p. 266)
}

Por meio de um levantamento em diversos trabalhos acadêmicos que versam sobre Modelagem Matemática no Brasil, Biembengut (2009) destacou o potencial da Modelagem em despertar no aluno interesse de forma mais ativa, culminando numa maior participação, cujo resultado será o alcance da construção do seu conhecimento matemático. Nesse sentido, vemos a dimensão motivacional que a Modelagem assume, capaz de produzir nos alunos interesses para aprender os conteúdos matemáticos que permeiam uma situação-problema das atividades de Modelagem. 
Para Barbosa (2001), a Modelagem à luz da Educação Matemática brasileira assume uma dimensão sociocultural a partir dos interesses e das áreas de realidade dos alunos. Tal dimensão é capaz de conduzi-los a um conhecimento além do matemático e tecnológico, o que é denominado como conhecimento reflexivo que, por sua vez, não pertence nem a corrente pragmática - aquela que argumenta que o currículo deve ser organizado em torno das aplicações —, nem a corrente científica de pensamento - aquela que busca estabelecer relações com outras áreas a partir da própria Matemática —, mas a uma terceira corrente conhecida como sociocrítica. Nessa corrente, a dimensão da Modelagem e papel do professor são redefinidos, uma vez que

\begin{abstract}
as atividades de Modelagem são consideradas como oportunidades para explorar os papéis que a matemática desenvolve na sociedade contemporânea. Nem matemática nem Modelagem são fins, mas meios para questionar a realidade vivida. Isso não significa que os alunos possam fazer complexas análises sobre a matemática no mundo social, mas que a Modelagem possui o potencial de gerar algum nível de crítica. É importante destacar que os alunos não transitam habitualmente para dimensão do conhecimento reflexivo, de modo que o professor possui grande responsabilidade fazê-los transitar (BARBOSA, 2001, p. 4).
\end{abstract}

Afere-se, portanto, que o papel do professor é guiar/mediar os alunos durante os processos de modelagem, cujo objetivo primeiro é promover a subsunção da Matemática com 0 ambiente sociocultural, mostrando que a Matemática não é um fim em si mesma. Ao reverso, é Ciência que dialoga com outras áreas de estudo.

Discutida a parte histórica, vamos nos debruçar agora sobre os conceitos específicos pertinentes à Modelagem Matemática. Segundo Bassanezi (2010), um modelo matemático é um conjunto de símbolos e relações matemáticas que representam de alguma forma o objeto estudado. Diversas outras definições podem ser encontradas na literatura. Para Biembengut e Hein (2005, p. 12), um modelo matemático é "um conjunto de símbolos e relações matemáticas que procura traduzir, de alguma forma, um fenômeno em questão ou problema de situação real". Já para McLone (1976), a ideia de um modelo é uma construção matemática abstrata, simplificada e que representa uma parte da realidade com um objetivo específico.

Em relação ao processo de Modelagem Matemática, Biembengut e Hein (2005) 0 descrevem como

o processo que envolve a obtenção de um modelo. Este, sob certa óptica, pode ser considerado um processo artístico, visto que para elaborar um modelo, além do conhecimento de matemática, o modelador precisa ter uma dose significativa de intuição e criatividade para interpretar o contexto, saber discernir que conteúdo matemático melhor se adapta e também ter senso lúdico para jogar com as variáveis 
envolvidas. (p. 12).

Uma proposta de atividade de Modelagem pode surgir por vários caminhos. Por vias matemáticas ou não, por sugestão do professor ou dos alunos. Barbosa (2001) sintetizou em quatro as etapas desse processo: formulação do problema, simplificação, coleta de dados e solução. Ao observar as tarefas que cabem ao professor e ao aluno em cada etapa, ele propõe três casos de experiências de Modelagem. Cabe ressaltar que os educadores divergem em relação a algumas etapas deste processo. Por exemplo, em relação à escolha do tema, para Bassanezi (2015) e Burak (2019), os alunos devem escolher os temas geradores e o professor, a partir dessas escolhas, deve ajudá-los a buscar as soluções matemáticas para o problema escolhido. Para Beltrão (2017) e Sadovsky (2007), a escolha do tema pelos alunos pode trazer dificuldades uma vez que na escola há um programa a ser seguido.

A situação-problema levada para sala de aula é uma ferramenta-chave importante para 0 desenvolvimento da Modelagem. Tais situações desencadeiam diversos questionamentos acerca de uma mesma problemática. Significa dizer que a situação-problema aplicada à Modelagem Matemática evidenciará as suas multifaces, tendo em vista que para ser respondida, será necessário o enfrentamento e busca de dados complementares para que se alcance o resultado pretendido.

Por sua própria natureza e por se tratar eminentemente de interrogações, ensejará reações motivacionais, apresentará cases facilitadores de aprendizagem, promoverá a integração com outras áreas de conhecimento, desenvolverá o trabalho coletivo e colaborativo, revelando-se como pêndulo de conexão com as questões socioculturais e com outras ciências.

Voltando para a discussão sobre os três casos de Barbosa (2001), nos primeiro e segundo casos, o professor é quem formula ou sugere o problema, enquanto que no terceiro caso 0 problema pode surgir por meio do professor, dos alunos, ou até mesmo de ambos. A simplificação e a coleta de dados no primeiro caso são sugeridas pelo professor, cabendo ao aluno interpretar, investigar e realizar, enquanto nos casos dois e três há diálogos entre o grupo e o professor para decidirem uma melhor forma de compreender e realizá-los. Por fim, a solução em todos os três casos é compartilhada com todos os envolvidos para que, a partir da discussão em grupo e do processo como um todo, possa ser promovida uma interpretação crítica da solução apresentada. 
Quadro 1: Distribuição das responsabilidades nas etapas da Modelagem

\begin{tabular}{|c|c|c|c|}
\hline Modelagem & $\mathbf{1}^{\mathbf{0}}$ caso & $\mathbf{2}^{\mathbf{0}}$ caso & $\mathbf{3}^{\circ}$ caso \\
\hline Formulação do problema & Professor & Professor & Professor/aluno \\
\hline Simplificação & Professor & Professor/aluno & Professor/aluno \\
\hline Coleta de dados & Professor & Professor/aluno & Professor/aluno \\
\hline Solução & Professor/aluno & Professor/aluno & Professor/aluno \\
\hline
\end{tabular}

Fonte: Barbosa (2001, p. 9)

No cenário da Educação Matemática brasileira, o terceiro caso é o mais recomendado pelos pesquisadores. Esse cenário estimula a participação do aluno em todas as etapas da Modelagem, compartilhando juntamente com o professor tarefas e responsabilidades. Esse caso possibilita explorar a Matemática crítica presente em projetos e atividades provenientes de outras áreas, mesmo aquelas sem relação direta com a Matemática.

Os caminhos possíveis para a realização de uma atividade com o uso de Modelagem, como pode ser visto acima, abrange diversos aspectos da aprendizagem e da motivação dos alunos envolvidos. Os trabalhos que utilizam a Modelagem Matemática em sala de aula vão muito além de fornecer uma simples resposta, sendo capazes de evidenciar aspectos dinâmicos da própria Matemática, como destaca Burak (2019):

\footnotetext{
Para a aprendizagem, o procedimento gerado a partir do interesse do grupo resulta em ganho, pois, os participantes trabalham com aquilo que gostam, que tem significado. Assim, assumem-se corresponsáveis pela aprendizagem. Sob essa ótica, o ensino de Matemática adquire mais dinamicidade, é mais vivo e, em consequência, mais significativo para cada estudante e, por isso, contribui para tornar mais intensa e mais eficiente a construção do conhecimento de determinado conteúdo por parte de cada participante, do próprio grupo e do professor, com fundamento no conhecimento individual incrementando 0 relacionamento interpessoal e interdisciplinar. A perspectiva da ampliação do conhecimento, e sua partilha envolve fraternal e solidariamente a todos. Há, ainda, maior dinâmica no ensino, pela ação e o envolvimento de todos. (p. 105).
}

Como podemos observar, o uso da Modelagem Matemática conduz o aluno a uma maior autonomia no conjecturar, no pensar e no agir, mediante a busca de uma solução para a situaçãoproblema, estimulado pela curiosidade e pela motivação; percebe-se, também, que pode não existir uma sequência pré-definida de conteúdo, haja vista que é a situação-problema que determina o que deve ser estudado. 


\begin{abstract}
A meu ver, o ambiente de Modelagem está associado à problematização e investigação. $O$ primeiro refere-se ao ato de criar perguntas e/ou problemas enquanto que o segundo, à busca, seleção, organização e manipulação de informações e reflexão sobre elas. Ambas atividades não são separadas, mas articuladas no processo de envolvimento dos alunos para abordar a atividade proposta. Nela, podemse levantar questões e realizar investigações que atingem o âmbito do conhecimento reflexivo. (BARBOSA, 2004, p. 75).
\end{abstract}

Essa oxigenação trazida para o ensino tradicional da Matemática apresenta certo viés humanizador, uma vez que traz para o seu bojo de estudo, discussão, questões antes salientadas. Quando o aluno é capaz de analisar as questões matemáticas postas e se utiliza de fatos que circundam o ambiente onde está inserido, ele é capaz de aprender e construir, por meio de seu próprio esforço, como se dá o processo de construção do modelo matemático. O próprio aluno, no exercício de sua análise, é capaz de criar o seu próprio processo de compreensão. Nesse modelo, o aluno é o protagonista na construção do seu saber.

\title{
3 O PROFMAT
}

O Mestrado Profissional em Matemática em Rede Nacional (PROFMAT) é um programa de mestrado semipresencial na área de Matemática com oferta nacional. É formado por uma rede de instituições de Ensino Superior, no contexto da Universidade Aberta do Brasil, em parceria com a Coordenação de Aperfeiçoamento Pessoal de Nível Superior (CAPES), sendo coordenado pela Sociedade Brasileira de Matemática (SBM), com apoio do Instituto Nacional de Matemática Pura e Aplicada (IMPA).

O PROFMAT foi criado em 2011 a partir de uma ação induzida pela CAPES junto à comunidade científica da área de Matemática, representada e coordenada pela SBM. O Programa tem como objetivo promover a formação continuada de professores das redes públicas de educação que busquem aprimoramento em sua formação profissional, com ênfase no domínio aprofundado de conteúdo matemático relevante para sua docência. Trata-se de um Programa no nível de pós-graduação stricto sensu com uso de tecnologias da educação a distância.

A seleção para o ingresso no Programa é realizada anualmente, sendo regulamentada em edital que fornece orientações e informações necessárias para a realização do Exame Nacional de Acesso (ENA).

Em relação ao seu projeto pedagógico, as atividades do Programa são realizadas presencialmente e a distância, organizadas em disciplinas obrigatórias, eletivas e finalização da 
dissertação de mestrado. As disciplinas obrigatórias do curso são Números e Funções Reais, Matemática Discreta, Geometria, Aritmética, Resolução de Problemas, Fundamentos de Cálculo e Geometria Analítica. O aluno deve ainda cursar duas disciplinas eletivas que podem ser escolhidas dentre 15 opções disponíveis. As atividades a distância podem ser realizadas por meio do ambiente virtual de aprendizagem, com o apoio dos recursos disponíveis na instituição associada e sob a responsabilidade do docente da disciplina.

Em 2011, ano de sua criação, o Programa era formado por 48 instituições, sendo ofertadas 1.192 vagas em 54 campi. Já no ano seguinte, quando a rede foi ampliada para 57 instituições, 0 PROFMAT alcançou todas as 27 unidades da federação. 0 número de vagas ofertadas e instituições seguiu crescendo e no ano de 2019 foram oferecidas 1.833 vagas, em 96 campi de 75 instituições.

O Programa vem sendo analisado por educadores e professores com o intuito de verificar sua eficácia e identificar possíveis deficiências. Em PROFMAT: avaliação de possíveis impactos (PROFMAT, 2018), são relatadas situações que mostram o potencial de melhoria nos processos de ensino e de aprendizagem nas escolas onde os egressos do Programa trabalham. Em um questionário direcionado aos diretores dessas escolas, 31\% relataram menores taxas de reprovação em turmas onde os professores lecionam; 35\% relataram um maior interesse dos alunos em Matemática; e a realização de mais atividades curriculares foi relatada em $47 \%$ dos casos. Em relação ao uso de práticas inovadoras de ensino, como novos instrumentos, ferramentas ou metodologias, $63 \%$ dos diretores opinaram que houve uma mudança positiva nesse quesito. No total, $95 \%$ dos diretores pontuaram no mínimo um impacto positivo do PROFMAT em sua escola, o que constitui um bom indicador da eficácia do Programa. Neste relatório também são apresentados dados que mostram um maior envolvimento dos professores egressos do PROFMAT nas Olimpíadas de Matemática; para 92\% dos diretores que responderam à pesquisa, houve maior incentivo dos professores para participação de seus alunos na Olimpíada Brasileira de Matemática das Escolas Públicas (OBMEP).

Caldatto, Fiorentini e Pavanello (2018) analisaram e discutiram o projeto acadêmico do PROFMAT, destacando a natureza dos conhecimentos formativos que são priorizados por essa política pública de desenvolvimento docente. Utilizando como base a teorização de Sacristán (2013), o artigo analisou o currículo oficial do Programa a partir de uma perspectiva curricular crítica e de pesquisas que investigam o conhecimento especializado do professor de Matemática. 
$\mathrm{Na}$ visão dos autores, as disciplinas do PROFMAT têm como foco a formação matemática dos professores e pouco investem em sua formação pedagógica e no conhecimento matemático para o ensino. Segundo os autores, as análises realizadas evidenciaram que esse Programa

privilegia a disseminação de códigos e conhecimentos vinculados fortemente à prática do matemático profissional, ao mesmo tempo que não aborda conhecimentos referidos pela literatura especializada como sendo fundamentais para a prática do professor que ensina matemática na educação básica. (CALDATTO, FIORENTINI E PAVANELLO, 2018, p. 260)

Já Vicente e Resende (2016) investigaram a relação entre o PROFMAT e a formação continuada de professores para a educação básica, na perspectiva das políticas públicas educacionais e, também, na perspectiva dos alunos do Programa. Segundo os autores, os participantes da pesquisa podem ser divididos em dois grupos: aqueles que consideram que 0 PROFMAT eleva o nível de conhecimento dos professores, produzindo um impacto positivo na docência, e aqueles que avaliam que o Programa enfoca a Matemática pura em um nível de complexidade que não é aplicável à realidade da escola.

Em relação à formação do egresso do Programa, os autores analisam que o PROFMAT dá ênfase aos

conteúdos específicos de matemática, sem abordar questões ligadas a técnicas pedagógicas ou outros saberes necessários à docência, relacionados ao contexto da escola no panorama educacional como um todo ou à complexidade social e familiar que permeia a vida dos jovens em idade escolar. (VICENTE e RESENDE, 2016, p. 205)

Como pode ser visto, o PROFMAT é um programa importante no cenário da formação continuada de professores, mas que vem sendo questionado principalmente em relação à sua pouca ênfase em transmitir conhecimentos didático-pedagógicos em suas disciplinas obrigatórias ou optativas. Neste artigo, entretanto, nosso foco estará voltado para os trabalhos de conclusão do Programa. Segundo Breda (2016),

\footnotetext{
o trabalho de conclusão de curso é um trabalho de reflexão final no qual o estudante deve mostrar, por meio de uma apresentação oral e pública, que, em alguma medida, alcançou os objetivos do PROFMAT, que o capacita para melhorar sua atuação como professor de matemática em um centro de Educação Básica. Nesse sentido, segundo as orientações do PROFMAT, o TCC deve ser um espaço para que se efetue um trabalho transversal contemplando boa parte dos saberes previstos no mestrado $(p$. 24).
}

Devido à abrangência nacional do Programa e da relevância dele na formação continuada 
de professores de Matemática, o banco de dados de dissertações do PROFMAT foi o escolhido, a fim de mapearmos como os trabalhos de conclusão de curso abordam a temática Modelagem Matemática como ferramenta metodológica de ensino. Na próxima seção, explicitaremos os aspectos metodológicos desse mapeamento.

\title{
4 Aspectos Metodológicos
}

Com o objetivo de obter uma visão global e compreender o que tem sido investigado com relação ao tema Modelagem Matemática no ensino nos trabalhos de conclusão de curso do PROFMAT, foi realizado um mapeamento dessas dissertações a partir do banco de dados do curso.

Por mapeamento, entenda-se o princípio metodológico descrito em Fiorentini et al. (2016), que entendem

\begin{abstract}
o mapeamento da pesquisa como um processo sistemático de levantamento e descrição de informações acerca das pesquisas produzidas sobre um campo específico de estudo, abrangendo um determinado espaço (lugar) e período de tempo. Essas informações dizem respeito aos aspectos físicos dessa produção (descrevendo onde, quando e quantos estudos foram produzidos ao longo do período e quem foram os autores e participantes dessa produção), bem como aos seus aspectos teóricometodológicos e temáticos (p. 18).
\end{abstract}

Da definição acima é possível perceber que um mapeamento não tem como objetivo realizar uma análise detalhada dos textos pesquisados, mas sim organizá-los de forma que seja possível obter uma compreensão clara sobre a maneira como um determinado fenômeno vêm sendo estudado, considerando características como: as temáticas, instituições em que foram produzidas, conteúdos matemáticos explorados e sujeitos da pesquisa, por exemplo.

A investigação foi realizada no banco de dissertações do PROFMAT ${ }^{1}$, realizada em 26 de abril de 2020. Este repositório somente permite realizar buscas a partir dos campos "Instituição", "Título" e "Aluno", não sendo permitida a pesquisa a partir das palavras-chave dos trabalhos. A pesquisa foi feita por meio do campo "Título", pesquisando pela palavra "Modelagem". Ressaltamos aqui a possibilidade de algum trabalho relacionado ao tema não estar incluído em nossa pesquisa, caso das dissertações em que a palavra "Modelagem" não consta dos títulos dos trabalhos. A escolha deste banco de dados se deu em função da importância que o Programa PROFMAT possui no cenário da formação continuada de professores de Matemática. Em especial,

\footnotetext{
1 Disponivel em http://www.profmat-sbm.org.br/dissertacoes.
} 
o Programa apresenta abrangência nacional, o que permite ter uma visão ampla sobre a forma como o tema vem sendo tratado no país. Foram pesquisadas dissertações relacionadas à Modelagem Matemática entre os anos de 2013 e 2019.

Para a análise dos dados foi utilizada uma metodologia quanti-qualitativa (GARNICA e PEREIRA, 1997), de modo que "o lado quantitativo refere-se aos dados numéricos dos quais lançamos mão para direcionar nossas conclusões - ainda que estas não sejam e nem mesmo as pretendamos definitivas. A quantidade, nesse caso, manteve-se como guia, nunca como determinante" (p. 61). Segundo a visão desses autores, utilizar uma metodologia qualitativa é fazer uma análise da qualidade das informações e não somente as quantidades dos dados, permitindo que a pesquisa possa traduzir reflexões e sensações presentes nos dados. Essa abertura quanto a exibir uma tradução dos dados é fundamental para o presente artigo, indo além de uma exibição quantitativa. Essa metodologia já é utilizada em outros trabalhos de mapeamento, como se pode ver em Esquincalha e Pinto (2018), por exemplo.

Com base na leitura e análise dos 140 trabalhos selecionados, foi possível agrupá-los de acordo com o nível de escolaridade, o ano, a região e a instituição onde o trabalho foi produzido. No âmbito da abordagem qualitativa, analisamos se os trabalhos tratam o tema de modo amplo e respaldados na literatura do tema. Além disso, apresentamos um exemplo de trabalho que corrobora com a análise qualitativa realizada.

\section{Visão Global dos Dados}

Das 140 dissertações mapeadas no âmbito do Mestrado Profissional em Matemática em Rede Nacional, o PROFMAT, que tratam do uso de Modelagem Matemática, 65\% são direcionadas ao Ensino Médio, 17\% aos Anos Finais do Ensino Fundamental, 17\% ao Ensino Superior e, adicionadas, as porcentagens de Anos Iniciais do Ensino Fundamental e a Formação Continuada de Professores correspondem a 1\%. A fim de auferir se um trabalho era direcionado ao Ensino Médio, nós verificamos se o trabalho propunha uma atividade prática direcionada para alguma das séries do Ensino Médio ou se o trabalho discute o uso de Modelagem Matemática como possibilidade de metodologia direcionada a esse nível de ensino. 0 mesmo critério foi utilizado para os demais níveis de escolaridade. 


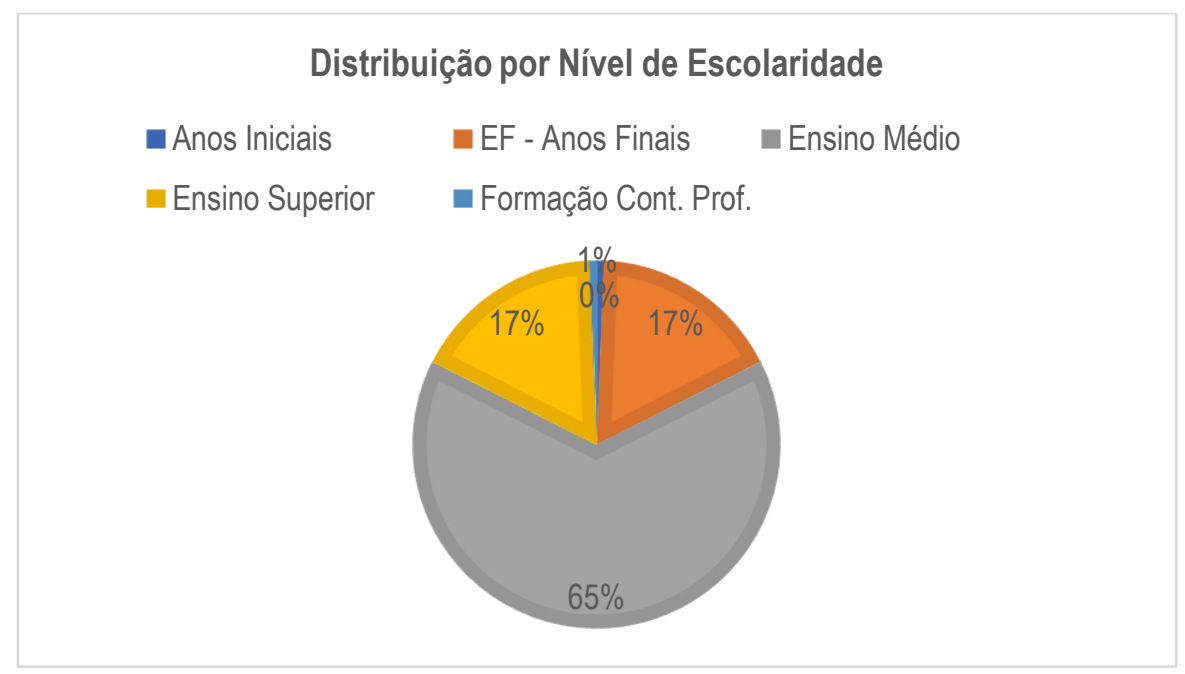

Figura 1: Distribuição por Nível de Escolaridade (Elaboração dos Autores)

A prevalência de trabalhos sobre Modelagem Matemática direcionadas ao Ensino Médio é corroborada com o seguinte dado: 50 trabalhos dos 140 mapeados tratam de alguma das funções estudadas no Ensino Médio — Função Afim, Função Modular, Função Quadrática, Função Exponencial, Função Logarítmica e Funções Trigonométricas. Nos trabalhos direcionados ao Ensino Superior, surgiram temas como: Cálculo de Derivadas, Equações Diferenciais e Modelos Populacionais, Probabilidades, Programação Linear, Grafos, Sistemas Dinâmicos e Métodos Numéricos. Já nos trabalhos direcionados ao Ensino Fundamental prevalecem os temas de funções e geometria plana. Os trabalhos estão distribuídos por ano de acordo com o gráfico na Figura 2.

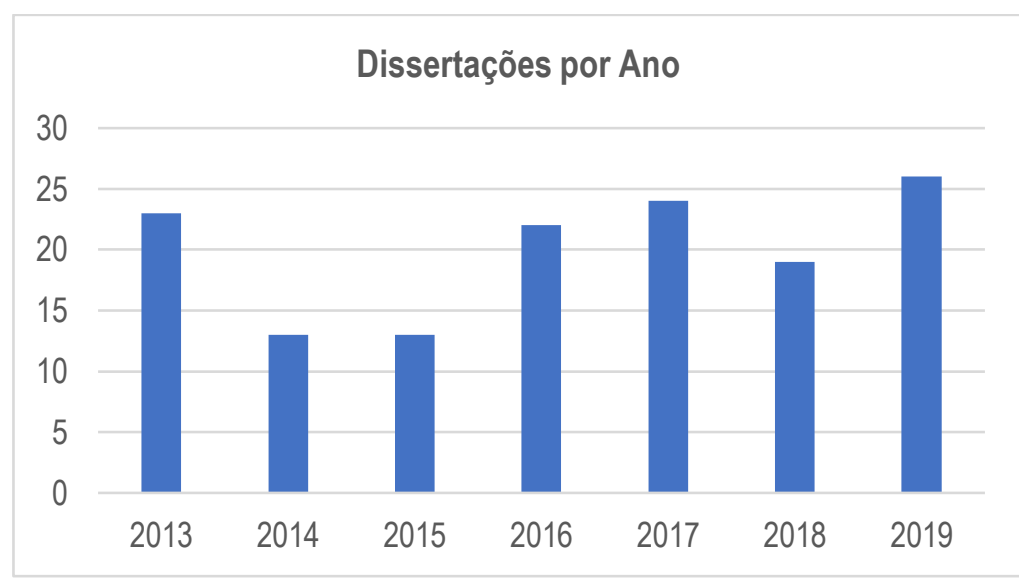

Figura 2: Distribuição de Dissertações por Ano (Elaboração dos Autores)

A Figura 2 indica uma tendência de aumento de trabalhos sobre Modelagem Matemática a partir de 2016. Os dados relativos também nos ajudam quanto à interpretação da situação real: de 2013 a 2015, 2,1\% das dissertações defendidas no PROFMAT versaram sobre Modelagem Matemática, enquanto de 2016 a 2019, foram 3,2\% de dissertações defendidas na temática. Esse 
aumento, apesar de pequeno, pode ser um indicativo da importância que a Modelagem Matemática vem ganhando nos últimos anos.

A distribuição de dissertações por estado é feita no gráfico ilustrado na Figura 3.

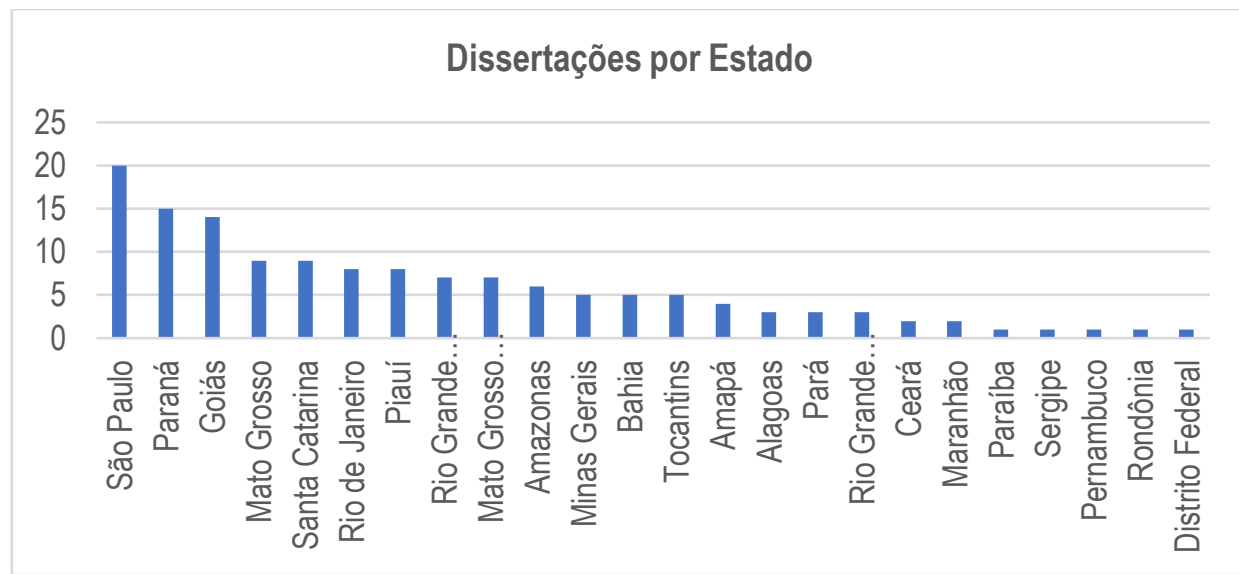

Figura 3: Distribuição de Dissertações por Estado (Elaboração dos Autores)

O gráfico dado na Figura 3 revela que, apesar de o Programa estar presente nos 26 estados federativos e no Distrito Federal, a Modelagem Matemática, ao menos no contexto do PROFMAT, ainda não alcançou todos os estados. Como podemos observar, os estados de São Paulo, Paraná e Goiás possuem a maior incidência de casos.

É interessante ver que os trabalhos estão bem distribuídos pelas regiões brasileiras, como mostra o gráfico da Figura 4.

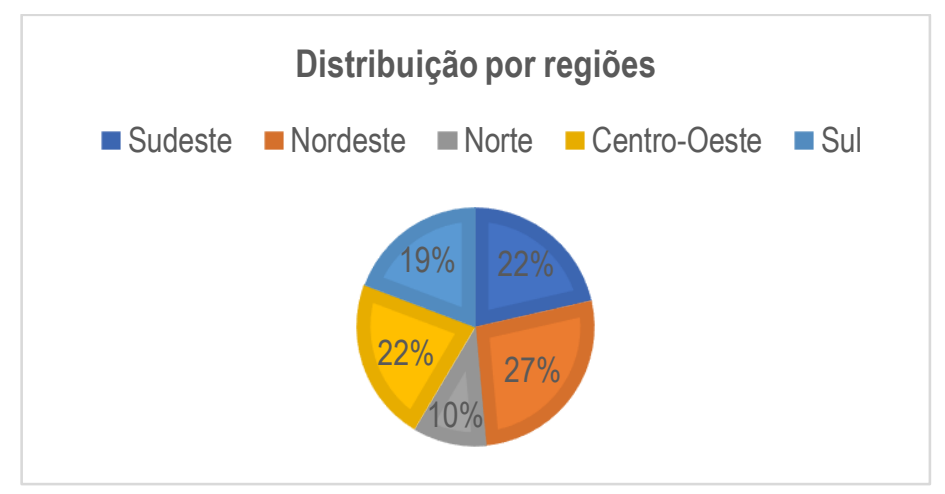

Figura 4: Distribuição de Dissertações por Região (Elaboração dos Autores)

O gráfico exibido na Figura 4 mostra uma distribuição por volta de $20 \%$ nas regiões Sudeste, Sul e Centro-Oeste. A região Nordeste se mostra a mais producente com relação ao tema no contexto do PROFMAT, tendo aproximadamente três vezes mais produções que a região Norte. Esse resultado se dá apesar de o Nordeste não possuir nenhum estado entre os cinco mais producentes - o Piauí, estado nordestino mais producente, é apenas o sétimo em cenário 
nacional —, indicando equilíbrio e espalhamento entre as produções dos estados nordestinos.

Os dados de dissertações por instituição de Ensino Superior são dados pelas Tabelas $1 \mathrm{e}$ 2.

Tabela 1: Distribuição de Dissertações por Instituição de Ensino Superior — Parte 1

\begin{tabular}{|c|c|c|c|c|c|c|c|c|}
\hline Instituição & UFG & UFMT & UNESP & UFERSA & $\begin{array}{c}\text { UFAM } \\
\text { UFMS } \\
\text { UFFS } \\
\text { UFPI }\end{array}$ & $\begin{array}{c}\text { UFPR } \\
\text { UFABC } \\
\text { UFT }\end{array}$ & $\begin{array}{c}\text { UNIFAP } \\
\text { UFRRJ }\end{array}$ & $\begin{array}{c}\text { UFPA } \\
\text { UFSC } \\
\text { UEPG } \\
\text { UFSM }\end{array}$ \\
\hline $\begin{array}{c}\mathrm{N}^{\circ} \text { de } \\
\text { Dissertações }\end{array}$ & 14 & 9 & 8 & 7 & 6 & 5 & 4 & 3 \\
\hline
\end{tabular}

Fonte: Dados da Pesquisa

Tabela 2: Distribuição de Dissertações por Instituição de Ensino Superior — Parte 2

\begin{tabular}{|c|c|c|c|c|c|c|c|}
\hline Instituição & $\begin{array}{c}\text { UEL } \\
\text { UFSJ } \\
\text { UFSCAR } \\
\text { UFAL }\end{array}$ & $\begin{array}{c}\text { UFTPR } \\
\text { UEM } \\
\text { UESB } \\
\text { UEFS }\end{array}$ & $\begin{array}{c}\text { UFCA } \\
\text { USP } \\
\text { UNIFESP }\end{array}$ & $\begin{array}{c}\text { UNIR } \\
\text { UFGD } \\
\text { UERJ } \\
\text { UFCG }\end{array}$ & $\begin{array}{c}\text { UESC } \\
\text { UFS } \\
\text { UNIM } \\
\text { UNICAMP } \\
\text { UFMA }\end{array}$ & $\begin{array}{c}\text { PUC/RJ } \\
\text { IMPA } \\
\text { UNIVASF } \\
\text { UFVJM }\end{array}$ & $\begin{array}{c}\text { IFPI } \\
\text { UESPI } \\
\text { UEMA } \\
\text { UNB }\end{array}$ \\
$\begin{array}{c}N^{\circ} \text { de } \\
\text { Dissertações }\end{array}$ & 3 & & 2 & & & 1 \\
\hline
\end{tabular}

Fonte: Dados da Pesquisa

Quanto à natureza qualitativa de nossa análise, um dado que salta aos olhos é que dentre todos os 140 trabalhos apenas um deles é puramente teórico, no sentido de não apontar nenhuma atividade e discutir apenas Modelagem Matemática como metodologia para o ensino de Matemática, além de discutir acerca de metodologias ativas. Os 139 demais trabalhos apresentam alguma atividade já realizada/testada ou não em sala de aula. No entanto, em média, cerca de $15 \%$ do total de páginas de cada trabalho se dedica a discutir Modelagem Matemática como possibilidade de metodologia no ensino de Matemática. Ainda sobre a discussão teórica apresentada nas dissertações, aproximadamente $26 \%$ dos trabalhos não apresentam sequer uma página de discussão sobre Modelagem como metodologia de ensino ou até mesmo uma revisão bibliográfica dos autores clássicos sobre Modelagem Matemática na Educação, se propondo a modelar problemas propostos durante o trabalho, apresentando, no entanto, a teoria matemática necessária para a realização da modelagem proposta.

Com relação aos objetivos das dissertações, praticamente todas consistem na elaboração de propostas de atividades para ensinar diferentes conceitos matemáticos de uma forma prática 
ou partindo de um problema real. Entretanto, como já mencionado, parte dos trabalhos não discute a aprendizagem matemática a partir de uma fundamentação teórica pertinente à área, limitandose a encontrar o modelo para o problema proposto durante o trabalho, no que se assemelha mais com o primeiro caso dos tipos de modelagem propostas por Barbosa (2001). Em alguns trabalhos, porém, não há nenhuma ou uma rasa análise da relevância daquela atividade na formação dos alunos que serão envolvidos. Outros trabalhos estão mais alinhados com a literatura da área, no sentido de exibirem uma revisão bibliográfica e refletirem na relevância da atividade em sala. Mesmo assim, nas dissertações que se propõem a realizar as atividades propostas em sala de aula, poucos trabalhos tratam dos dados de forma ampla com a bibliografia da área, discutindo a qualidade de cada uma das etapas e momentos das atividades de Modelagem Matemática como metodologia de ensino, limitando-se frequentemente a análises superficiais dos dados e resultados obtidos.

Em geral, muitas dissertações não apontaram para a formação do professor que ensina Matemática e apresentaram pouca discussão sobre as correntes da Educação Matemática, como a Matemática Crítica e a Etnomatemática, apenas para dar dois exemplos. Entendemos que 0 PROFMAT e todos os demais programas de formação inicial e/ou continuada de professores de Matemática devem possuir essa responsabilidade de pensar além do conteúdo matemático e refletir sobre o contrato didático estabelecido, se não nas disciplinas, ao menos no momento da pesquisa e escrita da dissertação, conforme a análise de Breda (2016). Essa responsabilidade não faz com que o trabalho deva necessariamente abrir mão em discutir conteúdos matemáticos, mas, sim, ao fazê-los, utilizar-se do aporte teórico das pesquisas relacionadas a prática do professor que ensina Matemática.

Breda (2016) estudou a melhoria na concepção dos professores que realizaram 0 PROFMAT no Rio Grande do Sul. A autora indica melhoria no ensino de Matemática a partir da reflexão de suas práticas, argumentando que embora alguns trabalhos sejam a simples elaboração de uma atividade, essa busca por fugir do tradicional pode despertar o interesse dos alunos e pode, assim, colaborar para o desenvolvimento profissional do professor. Em analogia, os trabalhos relacionados ao uso de Modelagem Matemática no PROFMAT podem contribuir para o processo formativo dos mestrandos no sentido de provocar alguma insatisfação do professor em simplesmente exibir um conteúdo no quadro. Apesar disso, reforçamos que ainda há um grande caminho a ser percorrido no que diz respeito à sistematização dos estudos realizados acerca de Modelagem e da avaliação na realização de atividades práticas. 
Para corroborar com a análise qualitativa realizada, apresentamos uma das dissertações investigadas. Na visão dos autores, esta dissertação desenvolve o tema de Modelagem Matemática de forma fundamentada nas propostas encontradas na literatura clássica do tema, apresentando metodologia adequada e separando sua abordagem nas etapas clássicas encontradas em uma atividade de Modelagem e focando na criatividade e autonomia do aluno.

A dissertação Uma aplicação da Modelagem Matemática na Educação do Campo de autoria de Ludyane de Fátima Dufeck e orientação de Elisângela dos Santos Meza foi realizada na Universidade Estadual de Ponta Grossa em 2017. Nela, há completude teórica e um contexto sem muitos recursos. Além disso, a atividade proposta durante o trabalho apresenta caráter interdisciplinar, pois contou com a colaboração de professores de outras áreas, como Língua Portuguesa e Ciências. O objetivo da dissertação, segundo a autora, era verificar se uma atividade de Modelagem Matemática, pode contribuir ou não para a formação dos alunos naquele contexto, mais especificamente, da Educação no Campo, no distrito de Guairacá do município de Guarapuava, cerca de $40 \mathrm{~km}$ de distância da cidade, aonde, em pesquisa preliminar, verificou-se que muitas famílias não tinham acesso a saneamento básico e outros serviços essenciais. Entre os objetivos específicos da dissertação destaca-se, além de ensinar conceitos como Geometria e Estatística, a construção, junto aos alunos, da proteção de uma nascente, para que eles pudessem reproduzir o procedimento com seus pais em suas propriedades rurais.

O trabalho começa com uma revisão bibliográfica da literatura acerca de Modelagem no contexto da educação no Brasil, passando pela teoria de Bassanezi (2010), Biembengut e Hein (2005). Após isso, discutiu a Educação no Campo e o caso da Educação do Campo no Paraná, trazendo, assim, referencial teórico padrão e assumindo viés metodológico consistente. Em seguida, o trabalho ainda se propôs a discutir a importância da qualidade da água, especialmente no meio rural, onde o acesso é mais problemático. $O$ trabalho faz ainda uma revisão dos conteúdos matemáticos necessários para a realização da atividade que viria mais adiante: Estatística, razão e proporção e Geometria Plana.

Quanto ao procedimento metodológico, a autora começou apresentando o Colégio Estadual do Campo Benedito de Paula Louro e a comunidade de 247 alunos envolvidos. Segundo a autora, a maioria dos alunos mora em fazendas, sítios e chácaras que estavam, em geral, distantes da escola. O Colégio contava ainda com um acesso precário à internet e uma biblioteca com escassez de funcionários. Quanto ao perfil profissional dos pais dos alunos, a autora observou 
profissões como lavradores (a maioria), operador de motosserra, merendeira, tratorista, motorista, dona de casa e boiadeiro. Em relação à escolaridade, pais e mães declararam possuir apenas Ensino Fundamental incompleto, em sua maioria.

A atividade prática que era realizada com os alunos no Colégio ocorria nos $7^{\circ}$ e $8^{\circ}$ anos do Ensino Fundamental. $O$ tema proposto pela professora foi a água. Diante da proposição, os próprios alunos levantaram as situações-problema que seriam estudadas e a professora iria orientar a atividade de acordo com esse levantamento das questões. Essa abordagem se assemelha com o terceiro caso dos estudos de Barbosa (2001), em que os alunos participam desde a escolha do problema, assim como na coleta dos dados, da simplificação e da resolução do problema posto. Os alunos precisaram realizar pesquisas em suas residências e seu distrito para obter dados acerca do tratamento da água e, além disso, foram levados a campo para coletar dados em grupo.

Na coleta de dados em grupo, os alunos deveriam calcular a vazão de uma nascente utilizando um balde e um cronômetro, para medir quanto tempo levava para que 0 balde preenchesse 10 litros. Em seguida, os alunos iniciaram uma limpeza e tratamento da nascente, retirando toda a sujeira e preparando a nascente para receber uma proteção.

Em sala de aula, os alunos precisaram analisar os diversos dados obtidos nas etapas do trabalho. Foram analisados vários dados como: distância das casas dos alunos até a escola e até a cidade de Guarapuava; a área total do local aonde o aluno mora; área utilizada nas residências para o plantio de cereais; área utilizada para reflorestamento; área utilizada para reflorestamento para fins comerciais; área de reservas ambientais; como era o esgoto da residência (fossa ou valeta); qual era o destino dado ao lixo (queimado, enterrado, coletado ou jogado no terreno); qual era 0 volume das caixas de água; qual era a origem da água nas residências (nascente, poço artesiano ou rio); qual era a distância aproximada da residência até a nascente mais próxima; qual era a profundidade do olho d'água; qual era o material utilizado para tampar o poço de água; quais motivos poluem a água da chuva; a frequência com que a água era coletada para análise; como a água era tratada; se era utilizado agrotóxico próximo à fonte e qual era a sua distância; como era realizada a limpeza próximo ao ponto de água; e qual era a área de mato ciliar próximo ao poço. Cada tópico acima foi sintetizado em tabelas e gráficos. Além dos gráficos, outros grupos de alunos também necessitaram construir maquetes, com um modelo de tratamento e proteção das nascentes. Durante toda a atividade, surgiram diversas dificuldades que foram resolvidas 
pelos alunos com a ajuda da professora. Incentivamos que o papel da professora deve ser de orientação e que os alunos possam agir com criatividade e inventividade na resolução dos problemas que possam surgir durante as etapas de uma atividade de Modelagem, a saber: na elaboração, na simplificação, na coleta de dados e na solução e validação dos resultados do problema.

Após todo o trabalho, os alunos precisaram apresentar seus resultados em sala de aula, explicando os resultados obtidos e qual era a importância de fazer um trabalho sobre o tema. Essa apresentação contribuiu para o período de avaliação da atividade, no que diz respeito a refletir sobre cada uma das etapas de uma atividade de Modelagem. Essa etapa constitui-se principalmente de uma análise coletiva sobre a validação dos resultados obtidos durante as várias etapas do trabalho e serve para socializar quais caminhos se saíram melhor ou pior comparados com outros. A autora conclui que

\begin{abstract}
ao ser utilizada Modelagem Matemática em três turmas diferentes, é plausível concluir que independentemente da quantidade de alunos, idade, rendimento escolar e conhecimento já adquirido, é possivel realizar o estudo e ensino de diferentes conteúdos matemáticos com base na Educação do Campo, com as adequações necessárias no que diz respeito a problematização apresentada pelos alunos, plano de trabalho docente, quantidade de aulas disponíveis e avaliações. Dessa forma, sugere-se que em possíveis trabalhos futuros, sejam utilizados outros temas pertinentes ao campo, como, por exemplo, reflorestamento, pecuária, artesanato e pesca, de acordo com a realidade dos alunos e dos conteúdos que pretende-se desenvolver e verificar se os resultados obtidos são satisfatórios." (DUFECK, 2017, p. 119).
\end{abstract}

O trabalho realizado na dissertação mostra-se laborioso, relevante em um contexto escolar e social complexos e necessitou de boa dose de criatividade para sua realização. Além disso, utilizou referencial teórico e metodologia adequada, buscando práticas consolidadas na literatura quanto a execução e avaliação das etapas, se mostrando bem amplo em sua análise.

\title{
6 Conclusão
}

Neste artigo foi realizado um mapeamento das dissertações de mestrado do programa PROFMAT que versavam sobre o tema Modelagem Matemática. A motivação para a escolha de tal tema surgiu da importância que a Modelagem Matemática vem adquirindo como metodologia de ensino de Matemática para tornar a disciplina mais atrativa e útil para os estudantes. 0 mapeamento dos trabalhos de conclusão de um importante programa como o PROFMAT nos 
permitiu ter uma visão global de como o tema vem sendo tratado pela comunidade de matemáticos e educadores.

No total foram encontrados 140 trabalhos, os quais foram classificados em relação ao nível de escolaridade ao qual se destinam, ano de produção, estado, região e instituição, além de identificar os temas mais abordados. Observamos que os trabalhos estão distribuídos entre as cinco regiões do país, havendo uma produção maior na região Nordeste, com $27 \%$ dos trabalhos produzidos e uma produção menor na região Norte, com apenas 10\% dos trabalhos.

A partir da análise e perspectiva dos trabalhos, observamos que muitos deles se enquadram no que Barbosa (2001) denomina como primeiro caso de Modelagem. A maioria dos trabalhos discute de forma superficial a importância da Modelagem Matemática como ferramenta de ensino. Parte dos trabalhos não discute a aprendizagem matemática a partir de uma fundamentação teórica pertinente à área, limitando-se a encontrar o modelo para o problema proposto durante o trabalho.

Diante disso, acreditamos que alguns dos trabalhos poderiam apresentar uma abordagem mais aprofundada da Modelagem Matemática, atribuindo importância a todas as etapas do processo, desde a escolha do tema a ser desenvolvido e a coleta de dados até a discussão dos resultados obtidos após a solução do problema. A realização cuidadosa e completa de todas as etapas do processo de Modelagem traz diversos benefícios para os processos de ensino e de aprendizagem, pois transforma o aluno em protagonista na criação do seu conhecimento matemático, atuando de forma mais ativa e reflexiva em todas as etapas da tarefa. Diversos trabalhos desenvolveram o tema de forma exemplar. Um desses trabalhos foi selecionado e realizamos uma apresentação mais profunda do mesmo, analisando-o em relação à sua classificação $-1^{\circ}, 2^{\circ}$ ou $3^{\circ}$ casos de Barbosa (2001) - e sua fundamentação na literatura existente sobre Modelagem Matemática para o ensino.

Esperamos que este artigo possa colaborar na difusão das ideias sobre Modelagem Matemática no ensino, atraindo novos adeptos e auxiliando os professores de Matemática em sua busca para tornar a sua disciplina mais atraente para os alunos e contribuir que os novos trabalhos caminhem para uma sistematização na metodologia e reflexão dos elementos que envolvam os trabalhos acerca da Modelagem Matemática. 


\section{Referências}

BARBOSA, Jonei Cerqueira. Modelagem Matemática: 0 que é? Por que? Como? Veritati, Salvador, n. 4, p. 73-80, 2004.

BARBOSA, Jonei Cerqueira. Modelagem na Educação Matemática: contribuições para o debate teórico. In: REUNIÃO ANUAL DA ASSOCIAÇÃO NACIONAL DE PÓS-GRADUAÇÃO E PESQUISA EM EDUCAÇÃO, 24, 2001, Caxambu. Anais da $24^{a}$ Reunião Anual da ANPEd. Rio de Janeiro: ANPEd, 2001, p. 1-15.

BASSANEZI, Rodney Carlos. Ensino-aprendizagem com Modelagem Matemática: uma nova estratégia. 3. ed. São Paulo: Contexto, 2010.

BASSANEZI, Rodney Carlos. Modelagem Matemática: teoria e prática. São Paulo: Contexto, 2015.

BELTRÃO, Maria Eli Puga. Ensino do Cálculo pela Modelagem Matemática: teoria e prática. Saarbrücken: Novas Edições Acadêmicas, 2017.

BIEMBENGUT, Maria Salett. 30 anos de Modelagem Matemática na educação brasileira: das propostas primeiras às propostas atuais. Alexandria, Florianópolis, v. 2, n. 2, p. 7-32, 2009.

BIEMBENGUT, Maria Sallet; HEIN, Nelson. Modelagem Matemática no ensino. 4. ed. Blumenau: Contexto, 2005.

BRASIL. Ministério da Educação. Secretaria de Educação Básica. Base Nacional Comum Curricular. Brasília: MEC/SEB, 2018.

BREDA, Adriana. Melhorias no ensino de Matemática na concepção de professores que realizam o mestrado PROFMAT no Rio Grande do Sul: uma análise dos trabalhos de conclusão de curso. 2016. 335f. Tese (Doutorado em Educação em Ciências e Matemática) — Faculdade de Física. Pontifícia Universidade Católica do Rio Grande do Sul. Porto Alegre.

BURAK, Dionísio. A Modelagem Matemática na perspectiva da Educação Matemática: olhares múltiplos e complexos. Educação Matemática Sem Fronteiras, Chapecó, v. 1, n. 1, p. 96-111, jan./jun. 2019.

CALDATO, Marlova Estela, FIORENTINI, Dario, PAVANELLO, Regina Maria. Uma análise do projeto de formação profissional de professores privilegiada pelo PROFMAT. Zetetike, Campinas, v. 26, n.2, p. 260-281, maio/ago. 2018.

COSTA, Felipe de Almeida. Ensino de Matemática por meio da Modelagem Matemática. Ensino da Matemática em Debate, São Paulo, v. 3, n. 1, p. 58-69, jan./jun. 2016.

DUFECK, Ludyane de Fatima. Uma aplicação da Modelagem Matemática na Educação do Campo. 2017. 136f. Dissertação (Mestrado Profissional em Matemática em Rede Nacional) Universidade Estadual de Ponta Grossa. Ponta Grossa.

ESQUINCALHA, Agnaldo da Conceição, PINTO, Gisela Maria da Fonseca. Mapeamento das dissertações sobre diversidade, diferença e inclusão produzidas no Mestrado Profissional em Matemática em Rede Nacional. Perspectivas da Educação Matemática, Campo Grande, v. 11, n. 
27, p. 667-684, set./dez. 2018.

FIORENTINI, Dario; GRANDO, Regina Célia; MISKULIN, Rosana Giaretta Sguerra; CRECCI, Vanessa Moreira; LIMA, Rosana Catarina Rodrigues; COSTA, Marina Carravero. In: FIORENTINI, Dario; PASSOS, Cármen Lúcia Brancaglion; LIMA, Rosana Catarina Rodrigues. (Org.). Mapeamento da pesquisa acadêmica brasileira sobre o professor que ensina matemática: período 2001 - 2012. Campinas: FE/Unicamp, 2016, p. 17-41.

GARNICA, Antônio Vicente Marafioti; PEREIRA, Maria Eliza Furquim. A pesquisa em Educação Matemática no Estado de São Paulo: um possível perfil. Bolema, Rio Claro, v. 11, n. 12, p. 59-74, 1997.

McLONE, Ronald Redman. Mathematical Modelling: the art of applying mathematics. Londres: Butterwords, 1976.

PROFMAT - MESTRADO PROFISSIONAL EM MATEMÁTICA EM REDE NACIONAL. PROFMAT: avaliação de possíveis impactos. Rio de Janeiro: PROFMAT, 2018.

SACRISTÁN, José Gimeno. O que significa o currículo. In SACRISTÁN, José Gimeno (Org.) Saberes e incertezas sobre o currículo. Tradução de Alexandre Salvaterra. Porto Alegre: Penso, 2013, p.16-38.

SADOVSKY, Patricia. O ensino da Matemática hoje: enfoques, sentidos e desafios. Tradução de Antônio de Pádua Danesi. São Paulo: Ática, 2017.

SONEGO, Gisele Vergínia. As contribuições da Etnomodelagem Matemática no estudo da Geometria Espacial. 2009. 143f. Dissertação (Mestrado em Ensino Ciências e Matemática). Centro Universitário Franciscano. Santa Maria.

VICENTE, João Pedro; RESENDE, Marilene Ribeiro. PROFMAT: um curso de formação de professores da educação básica? Revista Educação Pública, Cuiabá, v. 25, n. 58, p. 201-220, jan./abr. 2016. 